\title{
UNIVERSIDADE FEDERAL DO RIO GRANDE DO SUL
}

\section{CENTRO INTERDISCIPLINAR DE NOVAS TECNOLOGIAS NA EDUCAÇÃO}

III Ciclo de Palestras:

Novas Tecnologias na Educação

\section{MINICURSO}

\section{Título: CARTOLA - criando e recriando histórias na Internet}

Autores e sua experiência:

Margarete Axt (maaxt@ vortex.ufrgs.br)

Evandro Alves (evandarilho@yahoo.com.br)

Andrei R. Thomaz (andrei@ufrgs.br)

Carime Rossi Elias (carime@ terra.com.br)

Sílvia Meirelles Leite (illvia@vetorialnet.com.br)

Lucas Nunes Guimarães (terminator_linux@yahoo.com.br)

\section{Apresentação do Cartola}

O Cartola é uma atividade voltada para crianças em processo de alfabetização. Está disponível em www.lelic.ufrgs.br/cartola e é um ambiente lúdico voltado à criação e recriação de textos, articulando educação presencial e a distância via Internet por comunidades virtuais de aprendizagem. Sua estrutura possibilita que os usuários produzam histórias tanto individual quanto coletivamente, oportunizando a utilização do software por professores com grupos de alunos e entre grupos de escolas diferentes.

Quando o participante entra no software, encontra um espaço para escrever seu nome, o que será usado para identificar a autoria de quem produziu o texto. Logo após, acessa uma tela com três opções: Criar Texto, Ler Textos e Créditos.

Ao escolher Criar Texto, o participante encontra a imagem de uma cartola de mágico que, ao ser "clicada" faz com que surjam três elementos (uma figura, um som - que pode ser ouvido novamente clicando na imagem da orelha - e uma palavra) na tela. $\mathrm{O}$ participante é, então, convidado a escrever uma história a partir dos elementos apresentados. Tais elementos podem ser trocados por outros a qualquer momento bastando, para isso, um novo "clique" na figura da cartola (tanto para iniciar uma nova 
história, quanto para continuar a atual, articulando-a aos novos elementos sorteados). O espaço de escrita disponibilizado permite que o usuário salve seu texto, enviando-o para o banco de dados.

Quando o usuário clica em Ler Textos ele acessa o Banco de Textos do Cartola. Esse é constituído de uma tabela com os títulos dos textos criados, seus respectivos autores e datas de publicação. Através dessa interface, pode-se escolher qual o texto gostaria de ler e/ou dar continuidade, tanto os seus próprios quanto de outros autores. Ao escolher um texto para dar continuidade, o texto original permanece no Banco de Textos e uma nova versão é salva como outro arquivo.

Outro recurso oferecido pelo Cartola é a Interface para Pesquisadores. Para ter acesso a mesma é necessário possuir uma senha que permite o acompanhamento das diversas versões produzidas pelos usuários. Através dessa interface pode-se selecionar o IP que acessou o Cartola, escolher o autor que usou o IP selecionado (tendo em vista que em Instituições de Ensino várias pessoas podem usar a mesma máquina e compartilhar um mesmo IP) e visualizar os elementos usados (figura, som e palavra) para construir o texto, assim como os elementos sorteados, mas descartados pelo usuário. O público alvo deste módulo do Cartola são os próprios professores que estiverem trabalhando com os seus alunos e/ou eventuais pesquisadores que queiram desenvolver estudos sobre a produção de textos no ambiente.

A partir dos recursos descritos, o Cartola possibilita:

a. a construção de textos individuais e coletivos cujos processos, assim como as versões finais, ficam registrados no ambiente;

b. a armazenamento de textos, por parte dos usuários, que podem ser editados em outra oportunidade; bem como a edição de textos já iniciados por outros usuários, sendo este armazenado em um novo registro, de forma a preservar o texto original.

c. ao professor/pesquisador, através da Interface do Pesquisador, o acesso aos dados que poderão servir de corpus para análise, principalmente acerca do processo de construção de textos escritos.

Quanto à compatibilidade, o Cartola vem sendo desenvolvido para ter uma boa visibilidade em qualquer browser e que possa rodar e em diferentes sistemas operacionais. O único pré-requisito é o plug-in do Flash para se ver as animações. Além disso, o software, que foi projetado para uso na Internet, é facilmente adaptável para funcionar em Intranet ${ }^{1}$.

Do ponto de vista estético, o Cartola foi elaborado de forma que poucos comandos estejam disponíveis na tela, visando simplificar as opções de acesso e facilitar seu uso. O fator lúdico foi preponderante na escolha dos elementos gráficos que compõe o software. Em virtude dessa escolha, recorreu-se ao uso de cores fortes, sons e animação. Também se escolheu privilegiar espaços com desenhos em conjunto com a escrita, a fim de que os usuários possam ler tanto as imagens, quanto os comandos, sem restringi-los a textos extensos. Um exemplo disso está nos comandos de impressão,

\footnotetext{
${ }^{1}$ Desde que configurado em um servidor que suporte MySQL e PHP e em computadores na Intranet que permitam visualizar animações em Flash. 
texto novo e troca de figuras. Além dos elementos gráficos, recorremos ao uso do elemento aleatório que, incluído no jogo, constitui-se como fator de imprevisibilidade e compõe a dinâmica de utilização.

De uma perspectiva pedagógica, Cartola trata-se de um jogo. Porém, em uma concepção de jogo em que não há, necessariamente, ganhadores e perdedores. Trata-se, sim, de um jogo de linguagem, em que a criação e recriação individual e/ou coletiva de histórias na Internet realimenta, independente de quem tenha a última palavra, o próprio jogo.

O professor assume aqui papel ativo, pois cabe a ele, em conjunto com seus alunos, debater sobre regras e utilizações a partir da estrutura do software, que se pretende maleável. Nessa direção, o software pretende incitar a criação por parte das crianças escritoras, mas também pelo professor em sua prática pedagógica, no planejamento, implementação e avaliação das atividades de escrita mediada pelo Cartola.

Do ponto de vista das teorias de aprendizagem, o Cartola fundamenta-se na concepção construtivista/interacionista de Jean Piaget (1978). Ou seja, a aprendizagem é vista como um processo de construção (não como transmissão e apreensão de conhecimentos) que, em última instância, é individual (acontece por caminhos diferenciados em cada sujeito nas relações estabelecidas com o objeto), mas que é, ao mesmo tempo, potencializada pelas possibilidades de estabelecimento de interações cooperativas/ dialógicas com outros sujeitos.

\section{Súmula e tópicos a serem abordados:}

O minicurso envolve:

a) apresentação do Cartola;

b) interação com o ambiente e manuseio de seus recursos;

c) debate em torno de propostas com o uso Cartola.

\section{Objetivo:}

Propiciar aos participantes um embasamento teórico-prático necessário para a utilização do software Cartola.

\section{Metodologia:}

Essa proposta de minicurso de uso do software Cartola, parte da concepção interacionista piagetiana. Para tanto, o minicurso será estruturado da seguinte forma:

- apresentação do Cartola e de seus principais recursos;

- iniciar um texto com os elementos apresentados e salvá-lo;

- continuar o texto de outro participante;

- explorar a interface do pesquisador e suas possibilidades;

- debate presencial com o grupo em torno dos possíveis usos do cartola. 


\section{Referências Bibliográficas}

AXT, M. et al. (2002) Cartola. In: XIII Simpósio Brasileiro de Informática na Educação - XIII SBIE. São Leopoldo, RS. p. 663.

AXT, M.; et al. (2003) Produção coletiva em rede: é possível avaliar? Disponível em: http://www.cinted.ufrgs.br/renote/fev2003/artigos/margarete producao.pdf. Acessado em: agosto/2003.

AXT, M. et al. (2003) Cartola. In: XIV Simpósio Brasileiro de Informática na Educação - XIIV SBIE. Rio de Janeiro, RJ. p. 756-759.

COLLARES, Darli; ELIAS, Carime R. A Construção do Discurso Escrito conferências de escrita. In: Letras de Hoje. Vol 37, $\mathrm{n}^{\mathbf{o}}$ 2, p.99-110. Porto Alegre: EDPUCRS. Jun/2002.

FERREIRO, Emília ; TEBEROSKI, Ana. (1986) Psicogênese da Leitura e da Escrita. Porto Alegre: Artes Médicas. $6^{\mathrm{a}}$ ed.

PIAGET, J. (1978) A formação do símbolo na criança: imitação, jogo e sonho, imagem e representação. Rio de Janeiro: Zahar. 